\title{
GLOBAL DRUG-RESISTANCE PATTERNS AND THE MANAGEMENT OF LATENT TUBERCULOSIS INFECTION IN IMMIGRANTS TO THE UNITED STATES
}

\author{
Kamran Khan, M.D., M.P.H., Peter Muennig, M.D., M.P.H., Maryam Behta, Pharm.D., \\ and Joshua Graff Zivin, Ph.D.
}

\begin{abstract}
Background In the United States, an increasingly disproportionate burden of tuberculosis among the foreign-born population has led to calls for improvements in the detection and treatment of latent infection in new immigrants. Current treatment guidelines do not take into account global differences in drugresistance patterns or their implications for the treatment of immigrants. The use of multinational surveillance systems to guide the management of latent infection according to region-specific drug-resistance profiles could improve the efficiency of efforts to reduce the burden of tuberculosis in immigrants to the United States.

Methods We constructed a decision-analysis model by using a hypothetical cohort of all documented immigrants entering the United States from developing nations. Region-specific drug-resistance profiles were derived from data on 30,388 cases of infection. The model examined the effectiveness and cost effectiveness of four strategies: no intervention or tuberculin skin testing followed by treatment with isoniazid, treatment with rifampin, or treatment with rifampin plus pyrazinamide for those with a positive test result.

Results A strategy of detecting and treating latent tuberculosis infection was cost-saving among immigrants from Mexico, Haiti, sub-Saharan Africa, South Asia, and developing nations in East Asia and the $\mathrm{Pa}-$ cific. This strategy was highly cost effective among immigrants from other developing nations. Rifampin plus pyrazinamide was the preferred strategy for treating latent infection in immigrants from Vietnam, Haiti, and the Philippines.
\end{abstract}

Conclusions For new immigrants to the United States from developing nations, a strategy of detecting and treating latent tuberculosis infection would lead to substantial health and economic benefits. Because of the high prevalence of resistance to isoniazid, treatment with a rifampin-containing regimen should be strongly considered for immigrants from Vietnam, Haiti, and the Philippines. (N Engl J Med 2002;347: 1850-9.)

Copyright (c) 2002 Massachusetts Medical Society.

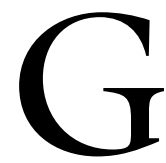
LOBAL migration is changing the international landscape of infectious diseases. ${ }^{1}$ In industrialized nations, immigration has become an increasingly important factor in the epidemiology of tuberculosis. ${ }^{2}$ In the United States, half of all cases of tuberculosis occur in foreign-born persons, ${ }^{3}$ who represent just 10 percent of the total population. ${ }^{4}$ Tuberculosis in the foreign-born population has been attributed largely to the importation of latent infection, with subsequent reactivation of disease. ${ }^{5}$ Recognizing that existing public health practices are inadequate, the Centers for Disease Control and Prevention (CDC) and the Institute of Medicine have both called for stronger measures to detect and treat latent infection in immigrants to the United States. ${ }^{6,7}$

As immigration policy is debated, 7,8 health care providers are faced with the challenge of managing latent infection in populations in which the prevalence of primary resistance to isoniazid can approach 30 percent. ${ }^{9,10}$ Despite concern regarding the effectiveness of isoniazid in certain foreign-born populations, ${ }^{11}$ no guidelines currently address the variation in drugresistance patterns among immigrants from different countries. Optimal treatment decisions should incorporate these factors, as well as information on adherence to drug-treatment regimens, adverse reactions, and costs. Because of the complexity of this decisionmaking process, the American Thoracic Society and the CDC have called for a cost-effectiveness analysis to address these issues. ${ }^{6}$

\section{METHODS}

\section{Overview and Definitions}

We constructed a hypothetical cohort of all documented immigrants 18 years of age or older who entered the United States from

From the Department of Public Health (K.K.), the Department of Medicine, Division of International Medicine and Infectious Diseases (K.K.), and the Department of Pharmacy (M.B.), New York Presbyterian Hospital and Weill Medical College of Cornell University, New York; the Program in General Public Health (K.K.) and the Department of Health Policy and Management (J.G.Z.), Joseph L. Mailman School of Public Health, and the International Center for Health Outcomes and Innovation Research (J.G.Z.), Columbia University, New York; and the Sophie Davis School of Biomedical Education, City University of New York, New York (P.M.). Address reprint requests to Dr. Khan at the Inner City Health Research Unit, St. Michael's Hospital, University of Toronto, 30 Bond St., Toronto, ON M5B IW8, Canada, or at km.khan@utoronto.ca. 
developing nations during the year 2000 for use in a decision-analysis model. The model was designed to assess the cost effectiveness of screening new immigrants for latent tuberculosis infection on entry to the United States and to identify optimal treatment strategies for persons with no history of active disease. Our analysis was conducted in adherence to the reference-case scenario outlined by the Panel on Cost-Effectiveness in Health and Medicine. ${ }^{12}$ All relevant costs and benefits were considered from the perspective of U.S. society, with the exception of those related to secondary transmission of infection or directly observed therapy. Future costs and benefits were discounted at a 3 percent rate and were half-cycle-adjusted.

\section{The Decision-Analysis Model}

A decision-analysis model that examined four strategies in the management of latent tuberculosis infection was constructed with the use of DATA 3.5 (TreeAge Software). The strategies were no intervention and tuberculin skin testing followed by one of three treatments for those with a positive test result: $300 \mathrm{mg}$ of isoniazid plus $25 \mathrm{mg}$ of pyridoxine daily for nine months, $600 \mathrm{mg}$ of rifampin daily for four months, or $600 \mathrm{mg}$ of rifampin plus 15 to $20 \mathrm{mg}$ of pyrazinamide per kilogram of body weight daily for two months.

A plausible range of high and low values for each variable was used to conduct sensitivity analyses that examined the influence of error in the values of variables on the results of the analysis. Monte Carlo simulations were also performed, in which values for all variables in the model were simultaneously varied over their plausible range, with values drawn from a probabilistically weighted triangular distribution. Principal assumptions and selected variables in the model are listed in Tables 1 and 2, respectively.

\section{Geographic Regions}

All data for the analysis were stratified according to the immigrants' origin in 13 geographically independent regions of the world. Seven of these regions included the nations from which approximately two thirds of all persons with tuberculosis among foreign-born persons in the United States originate: Mexico, the Philippines, Vietnam, India, China, Haiti, and South Korea. ${ }^{2}$ The six remaining regions were geoeconomic territories defined by the World Bank ${ }^{38}$ and comprised all developing nations other than those listed above in East Asia and the Pacific, South Asia, the Middle East and North Africa, Eastern Europe and Central Asia, sub-Saharan Africa, and Latin America and the Caribbean.

\section{Tuberculin Skin Testing}

The predictive value of a positive tuberculin skin test was calculated for each geographic region in the analysis. The sensitivity and specificity of the test were estimated with the use of a $10-\mathrm{mm}$ threshold and on the assumption of prior exposure to nontuberculous mycobacteria or vaccination with bacille Calmette-Guérin. The relative effect of such exposure on the specificity of the skin test was estimated from the medical literature ${ }^{27}$ and the consensus of experts. ${ }^{28}$ The prevalence of tuberculosis in each region was obtained from the World Health Organization (WHO). ${ }^{39}$

\section{Active Tuberculosis Infection}

The average number of adult immigrants entering the United States annually from each geographic region was calculated from nine years of immigration statistics. ${ }^{40}$ The postmigration incidence of active tuberculosis infection ${ }^{2,41}$ and the frequency of future disease relative to the time of entry into the United States were obtained from the CDC.42

The analytic horizon of the analysis was defined as the expected lifetime of the immigrant cohort entering the United States during 2000. This value was estimated by subtracting the median age of immigrants at the time of entry into the country ${ }^{40}$ from the average life expectancy of foreign-born persons living in the United States. ${ }^{43}$ The cumulative lifetime risk of active tuberculosis infection was es-
Table 1. Principal Assumptions of the Analysis.

The prevalence of latent infection among new immigrants reflects the prevalence of infection in their country of origin.

Drug-resistance patterns among new immigrants reflect resistance patterns observed in foreign-born persons in whom active disease develops within five years after entry into the United States.

Among immigrants who have latent infection on entering the United States, the development of active disease is due to the reactivation of infection acquired in the countries of origin. ${ }^{5}$

The treatment of latent infection provides lifelong benefit by reducing the subsequent risk of active disease. ${ }^{13}$

The treatment of latent infection with a drug to which the infecting pathogen is resistant provides no benefit in reducing the subsequent risk of active infection. ${ }^{14}$

Among immigrants treated for latent infection with rifampin plus pyrazinamide, the presence of resistance to either rifampin or pyrazinamide reduces the effectiveness of the combined regimen by 50 percent.

Given the current U.S. immigration policy, documented immigrants have a negligible risk of infection with the human immunodeficiency virus at the time of entry into the country. ${ }^{15}$

Deaths from active tuberculosis infection occur on average within two months after initial diagnosis.

Adverse drug reactions during the treatment of latent infection result in an unscheduled ambulatory care visit.

Immigrants from developing nations have been exposed to nontuberculous mycobacteria or have received bacille Calmette-Guérin before entering the United States

timated by the exponential formula $1-\mathrm{e}^{-\mathrm{I}(\delta \mathrm{T})}$, where $\mathrm{I}$ is the average postmigration incidence of active tuberculosis infection among immigrants with latent disease, and $\delta \mathrm{T}$ is the expected number of years of life after entry into the United States.

\section{Drug Resistance}

The prevalence of primary drug resistance was estimated for each region in the analysis by stratification of cases of active infection among foreign-born persons living in the United States according to country of origin. The estimates were derived from data on all cases of active infection reported to the CDC from each of the 50 states, New York City, and the District of Columbia during the five years from 1996 through $2000 .{ }^{44}$ To approximate more accurately the primary drug-resistance profiles of our hypothetical cohort, we considered only foreign-born persons 18 years of age or older who had resided in the United States for less than five years and who had no history of active infection. A total of 9550 cases met our inclusion criteria, and data on resistance to pyrazinamide were available for 75 percent of these cases. Resistance profiles according to the geographic region of origin are shown in Supplementary Appendix 1 (available with the full text of this article at http://www.nejm.org).

In order to enhance the geographic specificity of resistance profiles within each of the World Bank territories, ${ }^{38}$ data on primary resistance were also obtained from 26 nations participating in the Global Project on Anti-Tuberculosis Drug Resistance Surveillance ${ }^{9}$ or the EuroTB program ${ }^{10}$ between 1997 and 1999. A total of 20,838 cases were used to derive these national estimates after all persons with a history of active infection had been excluded from the analysis. Because pyrazinamide resistance was not reported, these data were used only for comparative analyses of the isoniazid and rifampin regimens. In total, 30,388 cases of infection were used to derive regional drug-resistance profiles.

\section{Morbidity and Mortality}

Changes in health-related quality of life due to active tuberculosis infection were derived with use of the Health Utilities Index. ${ }^{45}$ The 
Table 2. Selected Costs and Probabilities in the Decision-Analysis Model.*

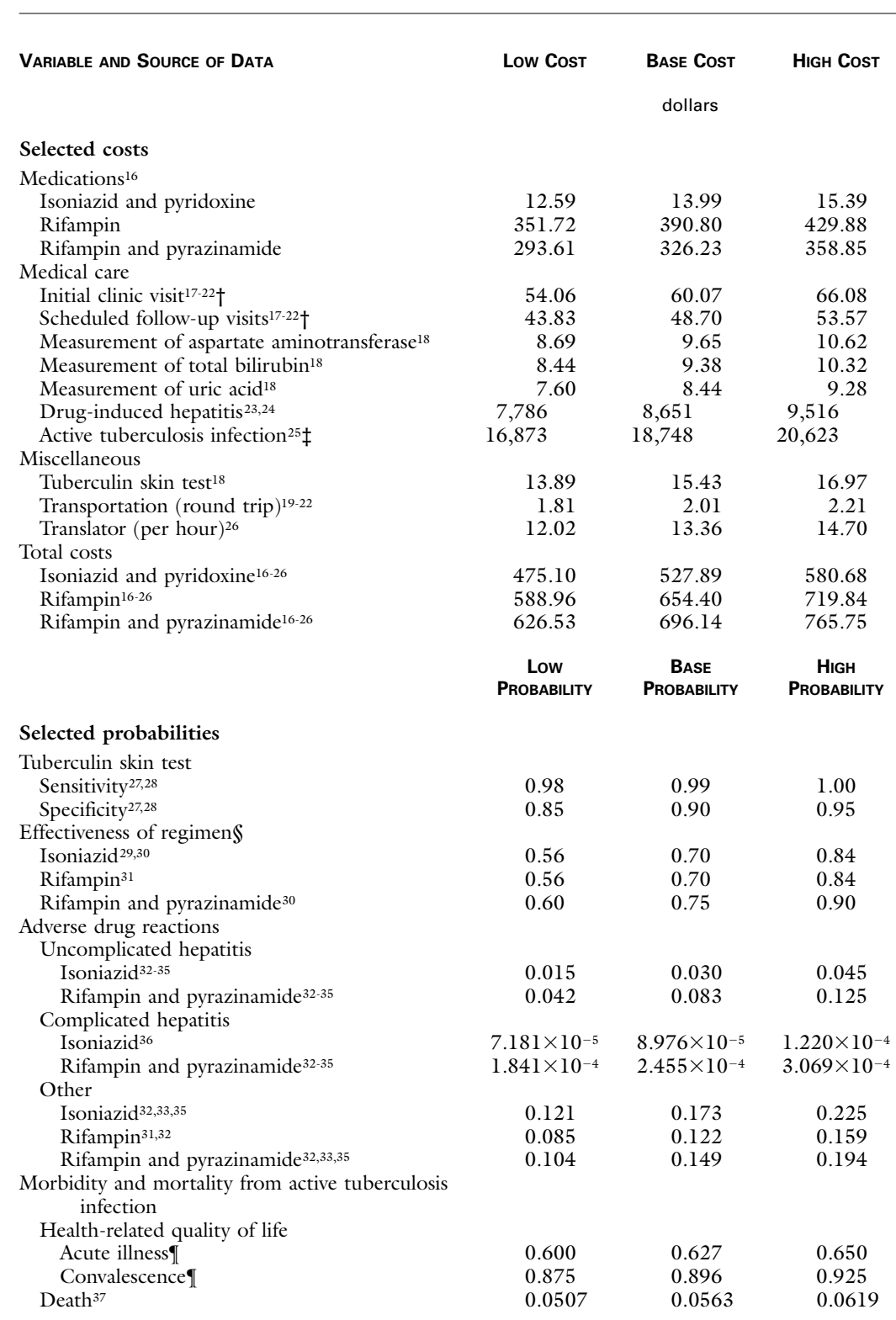

${ }^{*}$ The base estimate is considered the most probable value for each variable, while high and low estimates define the plausible range of values.

†Clinic visits include the costs of laboratory tests, transportation, services of interpreters, and the patient's time.

$\ddagger$ Future costs are discounted to present value.

§Effectiveness is calculated on an intention-to-treat basis.

IData are from an expert panel. 
values for this instrument were obtained from a panel of three infectious-disease specialists with expertise in tuberculosis. Mortality statistics for persons with active infection were obtained from the National Center for Health Statistics. ${ }^{37}$

\section{Effectiveness of the Regimen}

The effectiveness of each regimen was determined from clinical trials in the medical literature ${ }^{29-31}$ and was adjusted for the estimated prevalence of drug resistance within the populations participating in those clinical trials. ${ }^{30,31}$ We estimated this prevalence using surveillance data from the medical literature, ${ }^{46}$ the $\mathrm{CDC},{ }^{47}$ and the $\mathrm{WHO},{ }^{9}$ after taking into consideration the country in which the clinical trial was conducted, the calendar year of the trial, and the participants' status with respect to infection with the human immunodeficiency virus (HIV). The influence of incomplete adherence on the effectiveness of treatment was incorporated into the analysis through the use of intention-to-treat analyses.

\section{Costs and Charges}

Costs attributable to transportation, ambulatory care, services of interpreters, laboratory tests, medications, adverse drug reactions, hospitalization, and patients' time were included in the analysis in adherence to current national guidelines for the management of latent ${ }^{6,48}$ and active ${ }^{49}$ tuberculosis infection. All transportation costs were adjusted to account for the estimated proportion of the population that would be driving, using public transportation, or traveling by other means, such as bicycling or walking. ${ }^{19}$

The base cost of an ambulatory care visit was estimated on the basis of the national average Medicare reimbursement rate in 2000 for a focused medical evaluation requiring 15 minutes of a physician's time. ${ }^{17}$ The costs of a medical interpreter ${ }^{26}$ were added for immigrants unable to speak English fluently. ${ }^{4}$ The costs of medication were calculated from the average wholesale prices of pharmaceuticals. ${ }^{16}$

The costs and frequency of adverse drug reactions were estimated from the medical literature. ${ }^{31-36}$ The frequency of hepatitis attributable to the use of rifampin plus pyrazinamide was estimated on the basis of data from clinical trials conducted in predominantly HIV-negative populations. ${ }^{32-35}$ The projected numbers of cases of severe hepatitis for each geographic region are given in Supplementary Appendix 2 (available with the full text of this article at http://www.nejm.org).

Hospital charges and the average length of stay for persons with drug-induced hepatitis were estimated on the basis of data from the Healthcare Cost and Utilization Project, ${ }^{23}$ and the Medicare Provider and Analysis Review ${ }^{24}$ was used to convert hospital charges into costs to society. The average cost of treatment per case of active tuberculosis infection was derived from a national study. ${ }^{25}$

The costs of patients' time were estimated from national data on the median salaries of foreign-born persons living in the United States. ${ }^{50}$ Time spent in travel and receiving medical care was included in the estimates. When applicable, medical and nonmedical costs were adjusted to U.S. dollars for the year 2000 with use of the Consumer Price Index. ${ }^{.1}$

\section{RESULTS}

The total net costs, the expected number of tuberculosis cases, the number of quality-adjusted life-years gained, and the cost effectiveness of each management strategy for immigrants from each geographic region and all developing nations are shown in Table 3. Figure 1 shows the optimal treatment regimen or regimens for immigrants from various regions, both with and without contraindications to rifampin plus pyrazinamide, ${ }^{48}$ according to our analysis.
Our analysis indicated that a strategy of detecting and treating latent tuberculosis infection among immigrants from Mexico, Haiti, Vietnam, the Philippines, China, South Korea, sub-Saharan Africa, South Asia, and other developing nations in East Asia and the Pacific would result in both health benefits and economic savings. Since our model predicted that treatment with rifampin would be less effective and more expensive than treatment with rifampin plus pyrazinamide for all regions, rifampin monotherapy was considered a "dominated" strategy when all treatment options were available. For immigrants from Vietnam, Haiti, and the Philippines, our model predicted that rifampin plus pyrazinamide would be the most effective and least expensive treatment option and thus was the preferred strategy for those regions.

Our sensitivity analyses showed that, if the effectiveness of isoniazid was at least 22 percent greater than that of rifampin plus pyrazinamide in immigrants from Vietnam, or at least 16 percent greater in immigrants from Haiti or the Philippines, isoniazid would become the preferred treatment strategy for those nations. If, on the other hand, a two-month course of rifampin plus pyrazinamide could be purchased for less than $\$ 217$, it would replace isoniazid as the preferred treatment strategy for immigrants from developing nations overall. Sensitivity analyses of other influential variables in the model are presented in Table 4.

Monte Carlo simulations conducted for each geographic region indicated that the treatment strategies recommended in our analysis (Fig. 1) were dominated in fewer than 5 percent of all trials performed, thus reinforcing the fact that our findings were robust with respect to error in all variables in the model.

\section{DISCUSSION}

Our analysis indicates that a strategy of screening immigrants from developing regions of the world for latent tuberculosis infection at the time of their entry into the United States could result in substantial health and economic benefits. Our model predicts that, if such a strategy were implemented for a single year, approximately 9000 to 10,000 cases of active tuberculosis infection would be averted, and $\$ 60$ million to $\$ 90$ million would be saved. Although these benefits would accrue over the expected lifetime of a cohort of immigrants who entered the United States during a given year, approximately half of the total benefit would be realized within six years. Moreover, because our analysis did not consider costs attributable to directly observed therapy or to the secondary transmission of infection, our projection of financial savings may substantially underestimate the true benefits of screening.

Our study had several limitations. Foremost was our 
Table 3. Cost Effectiveness of Treatment of Latent Tuberculosis Infection According to the Patient's Geographic Region of Origin.*

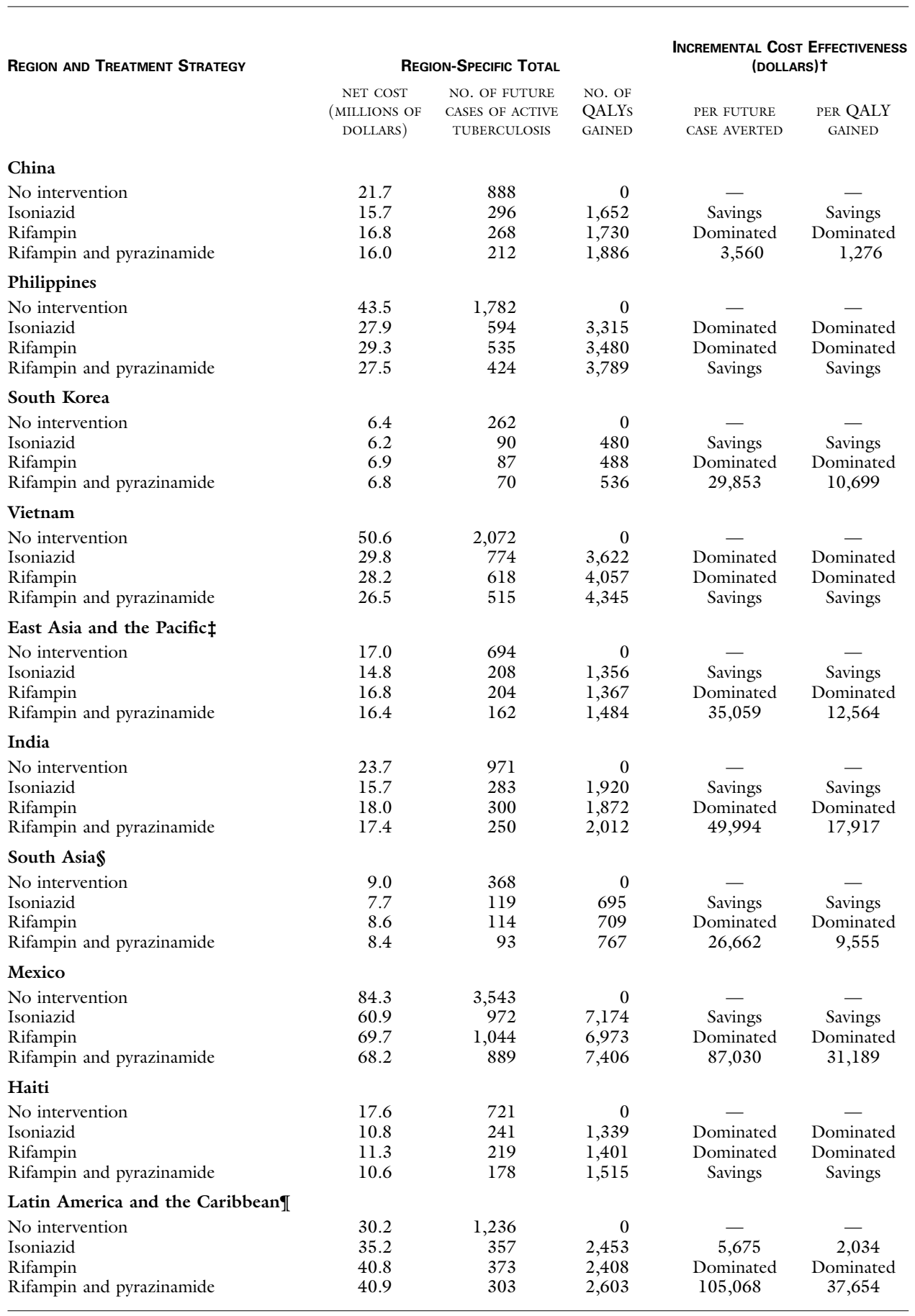

1854 • N Engl J Med, Vol. 347, No. 23 • December 5, $2002 \cdot$ www.nejm.org 
Table 3. Continued.

Region and Treatment Strategy

\begin{tabular}{ccc}
\multicolumn{3}{c}{ Region-SPecific Total } \\
NET COST & NO. OF FUTURE & NO. O \\
(Millions OF & CASES OF ACTIVE & QALY \\
DOLLARS) & TUbERCULOSIS & GAINE
\end{tabular}

Eastern Europe and Central Asia

No intervention

Isoniazid

Rifampin

Rifampin and pyrazinamide

Middle East and North Africa

No intervention

Isoniazid

Rifampin

Rifampin and pyrazinamide

Sub-Saharan Africa

No intervention

Isoniazid

Rifampin

Rifampin and pyrazinamide

All developing nations

No intervention

Isoniazid

$\$ 10,000$ per QALY
InCRemental Cost Effectiveness

(DOLLARS) $†$

PER FUTURE PER QALY

CASE AVERTED GAINED

$\begin{array}{cc}5,952 \\ \text { Dominated } & \text { Dominated }\end{array}$

$149,978 \quad 53,388$

\begin{tabular}{|c|c|c|c|c|}
\hline 9.2 & 378 & 0 & - & - \\
\hline 13.7 & 105 & 762 & 16,522 & 5,952 \\
\hline 16.0 & 112 & 742 & Dominated & Dominated \\
\hline 16.1 & 89 & 289 & 149,978 & 53,388 \\
\hline 8.4 & 343 & 0 & - & - \\
\hline 9.0 & 100 & 678 & 2,551 & 914 \\
\hline 10.4 & 108 & 656 & Dominated & Dominated \\
\hline 10.4 & 89 & 709 & 129,401 & 46,374 \\
\hline 16.5 & 675 & 0 & - & - \\
\hline 10.9 & 203 & 1,317 & Savings & Savings \\
\hline 12.1 & 200 & 1,325 & Dominated & Dominated \\
\hline 11.5 & 160 & 1,437 & 13,826 & 4,955 \\
\hline 338.1 & 13,933 & 0 & - & - \\
\hline 258.3 & 4,342 & 26,763 & Dominated & Dominated \\
\hline 256.0 & 3,697 & 28,562 & Savings & Savings \\
\hline
\end{tabular}

*QALY denotes quality-adjusted life-year. All costs are presented in U.S. dollars for the year 2000 and are rounded to the nearest $\$ 100,000$. Dominated strategies are both less effective and more expensive than their competing strategies and thus should not be adopted. Cost-saving interventions ("Savings") are those that result in both health benefits and financial savings.

$\dagger$ Dashes indicate the reference category for the first nondominated strategy.

‡China, the Philippines, South Korea, and Vietnam are excluded.

\$India is excluded.

IMexico and Haiti are excluded.

$\|$ The most effective strategy is adopted for each geographic region up to an incremental cost-effectiveness ratio of $\$ 10,000$ per quality-adjusted life-year.

inability to distinguish between documented immigrants and other foreign-born persons, because of the manner in which national surveillance data are collected in the United States. Since immigration status is not a component of tuberculosis case reporting, we were limited in our ability to identify possible differences among subgroups of foreign-born persons.

Our study was also limited by a lack of populationlevel data on the hepatotoxicity of daily rifampin plus pyrazinamide. Recent reports have aroused concern about the safety of this regimen in HIV-negative persons; however, in a recent study of 589 prison inmates, most of whom were HIV-negative, a twice-weekly regimen was well tolerated. ${ }^{52}$ In our analysis, we obtained the most current data available from four studies that evaluated daily doses ${ }^{32-35}$ and then broadly examined the effects of variation in hepatotoxicity in our sensitivity analysis. We also considered the possibility that chronic viral hepatitis, which is endemic in many re- gions of the developing world, might increase the risk of drug-induced hepatitis. Although such an effect is biologically plausible, observational studies of populations chronically infected with hepatitis $\mathrm{B}$ or hepatitis $\mathrm{C}$ have not found an elevated risk with isoniazid. ${ }^{53,54}$

We assumed that cultural differences among immigrant groups were unrelated to adherence and thus to the effectiveness of drug regimens. The alternative assumption would have required us to make cultural generalizations about adherence, which we believe would be unethical. Moreover, if culturally appropriate education were an integral component of the treatment for latent infection in immigrants, the relevance of potential cultural differences could be minimized.

All the data on resistance in our analysis came from surveillance programs conducted between 1996 and 2000 , raising the possibility that these data might not reflect current global trends. National data, however, indicate that substantial changes in the prevalence of 

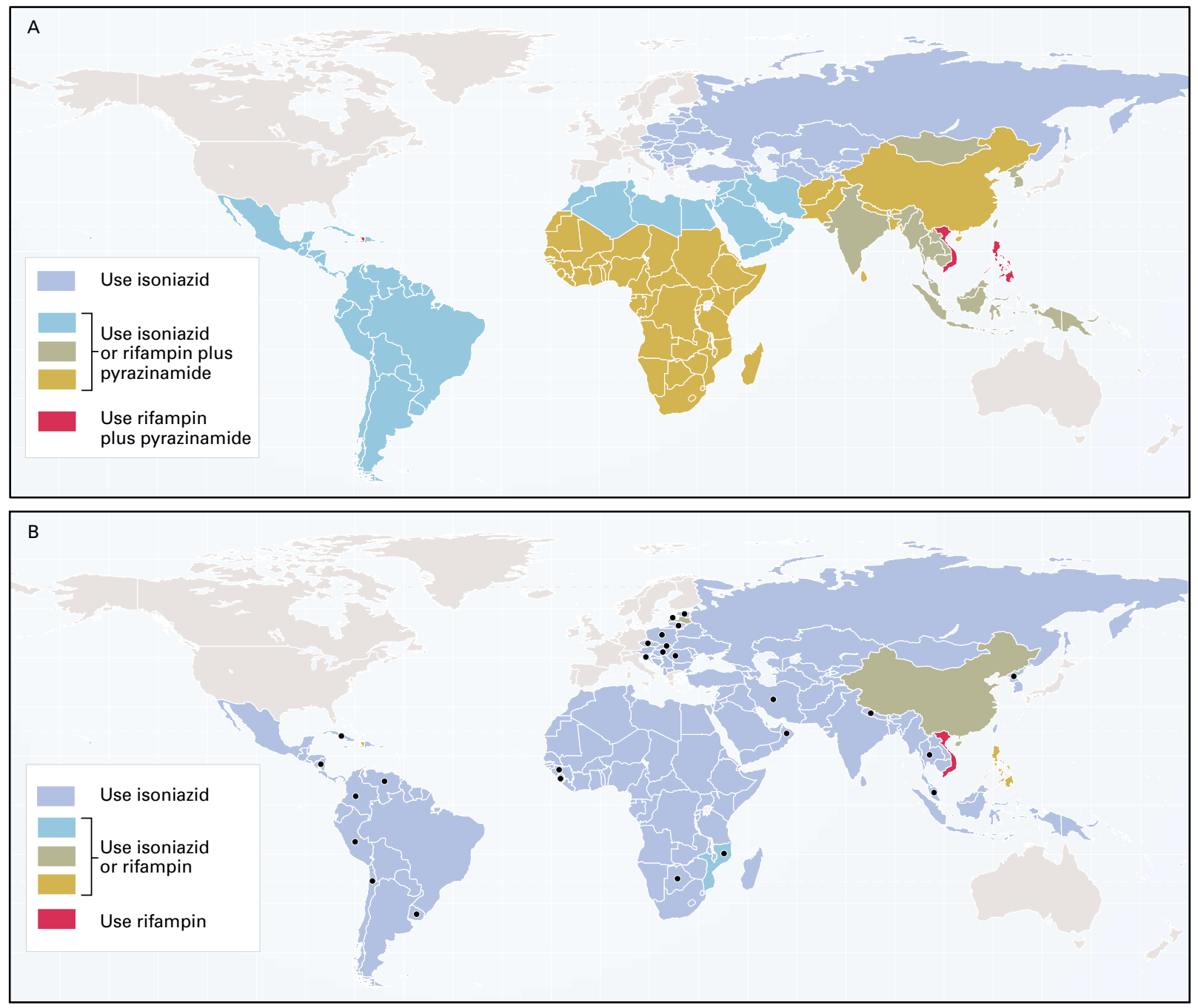

Figure 1. Recommended Treatment Strategies for Immigrants to the United States with Latent Tuberculosis Infection According to Geographic Region of Origin.

Panel A shows treatment strategies for patients without contraindications to rifampin plus pyrazinamide. For patients from red areas, rifampin plus pyrazinamide is recommended. For patients from turquoise, olive, or tan areas, isoniazid or rifampin plus pyrazinamide is recommended. For patients from blue areas, isoniazid is recommended. Panel B shows treatment strategies for patients for whom the use of rifampin plus pyrazinamide is contraindicated. For patients from red areas, rifampin is recommended. For patients from turquoise, olive, or tan areas, isoniazid or rifampin is recommended. For patients from blue areas, isoniazid is recommended. Smaller nations of importance include Haiti (red in Panel A, tan in Panel B) and Latvia (olive in Panel B). The maps were generated by using Epi Info 2000 version 1.1.2 for Windows (Centers for Disease Control and Prevention).

For patients from tan areas, rifampin plus pyrazinamide (Panel A) or rifampin alone (Panel B) should be used if there is willingness to pay an incremental cost of $\$ 10,000$ per quality-adjusted life-year gained relative to isoniazid. For patients from olive areas, rifampin plus pyrazinamide (Panel A) or rifampin alone (Panel B) should be used if there is willingness to pay an incremental cost of $\$ 25,000$ per quality-adjusted life-year gained relative to isoniazid. For patients from turquoise areas, rifampin plus pyrazinamide (Panel A) or rifampin alone (Panel B) should be used if there is willingness to pay an incremental cost of $\$ 50,000$ per quality-adjusted life-year gained relative to isoniazid. Areas associated with incremental cost-effectiveness ratios exceeding $\$ 50,000$ per qualityadjusted life-year are shown in blue.

Black dots in Panel B indicate nations participating in the Global Project on Anti-Tuberculosis Drug Resistance Surveillance ${ }^{9}$ or the EuroTB program.10

1856 - N Engl J Med, Vol. 347, No. 23 • December 5, $2002 \cdot$ www.nejm.org 
Table 4. Threshold Values from One-Way Sensitivity Analyses. *

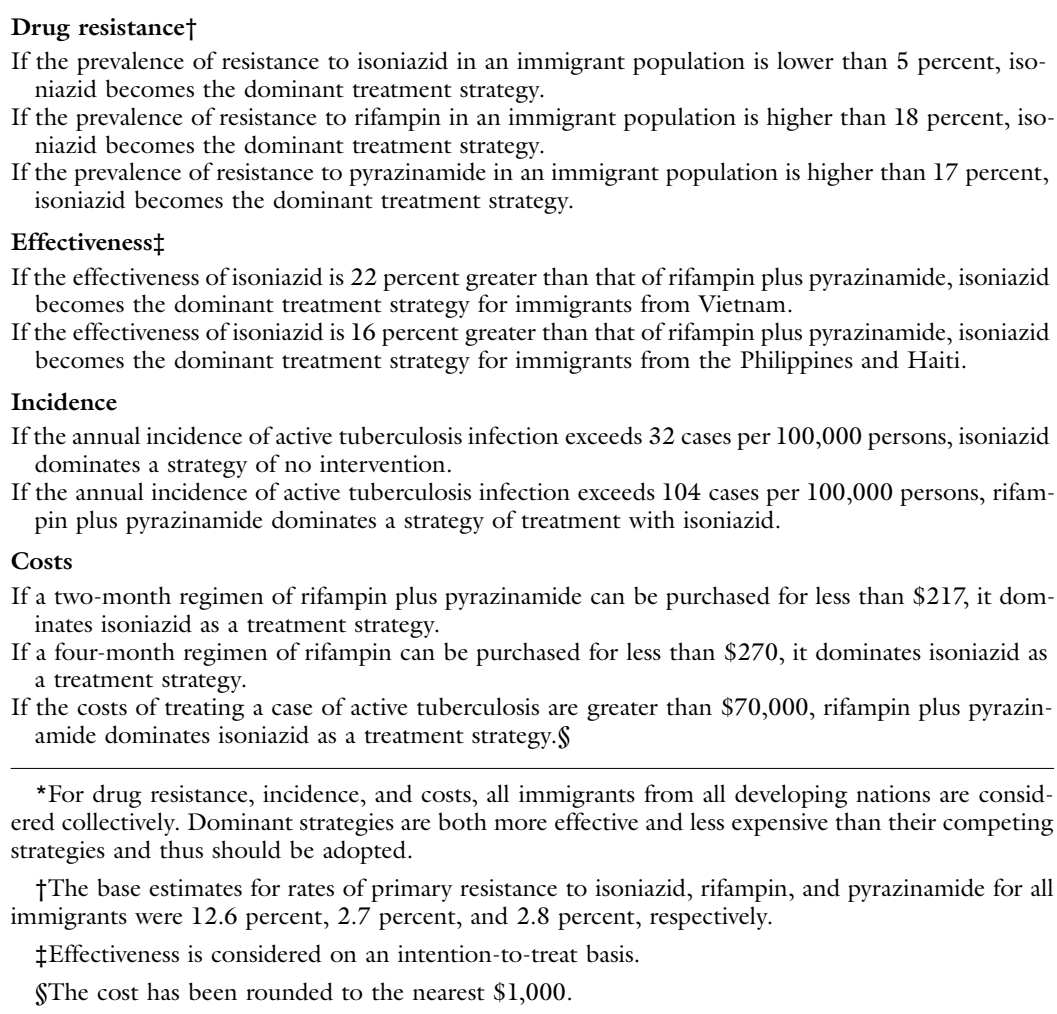

drug resistance were not observed in specific foreignborn populations in the United States during a recent five-year period. ${ }^{5}$ Moreover, future trends in drug resistance could be addressed as new data become available.

Because of the absence of a surveillance system for latent tuberculosis infection in the United States, our analysis relied on data from the WHO to estimate the international prevalence of tuberculosis infection. ${ }^{39}$ Although it is possible that the risk of latent infection might differ between immigrants and populations of the countries from which they came, no studies, to our knowledge, have specifically addressed this issue. However, when we broadly tested the effect of uncertainty in the prevalence of latent infection in our sensitivity analysis, we observed similar effects in each of the treatment groups, so that there were no changes in the qualitative conclusions of our analysis.

We were also limited by a lack of data regarding the effectiveness of rifampin plus pyrazinamide in patients with resistance to either drug. For example, we did not wish to exclude the possibility of benefit from rifampin alone in the presence of isolated pyrazinamide resistance, since clinical data exist to demonstrate the benefits of rifampin monotherapy. ${ }^{31}$ Therefore, we assumed that resistance to either drug would reduce the effectiveness of the combined regimen by 50 percent. When we tested this assumption in our sensitivity analysis, we found no effect on the rank order of our outcomes, even if two months of rifampin alone or of pyrazinamide alone were to provide no benefit whatsoever.

Finally, our analysis assumed that persons with HIV infection would be excluded from legal immigration in accordance with current U.S. policy. ${ }^{15}$ In practice, however, some immigrants with HIV might not be identified by the current screening system. Since higher rates of HIV infection would increase the risk of active tuberculosis, the benefits of treatment of latent infection would only be greater if a large number of immigrants were HIV-positive.

Our study was designed to address the increasingly disproportionate burden of tuberculosis among foreign-born persons in the United States, but the challenges are similar for other industrialized nations. Although the findings of our study regarding effectiveness should be generalizable to other countries, our economic analysis was specific to the United States. 
Future analyses, however, may be required to reflect the screening policies, immigration patterns, and health care systems of other nations.

The general analytic framework of our analysis could be applied to other infectious diseases for which heterogeneous drug-resistance patterns are important. Use of antimicrobial agents could then be better targeted to local drug-resistance patterns, thereby improving effectiveness, reducing costs, and possibly delaying the development of drug resistance.

As we enter the 21st century, new approaches must be developed to address the globalization of infectious diseases. ${ }^{1}$ Although immigration policy is an integral component of national public health, ${ }^{7}$ careful attention should be given to safeguarding the civil liberties of new immigrants, ${ }^{8}$ and great efforts made to avoid excessive financial or bureaucratic burdens that could delay and impair the process of acculturation. As the United States and other industrialized nations strive to eliminate tuberculosis, the global forces driving this disease - namely, poverty and HIV - remain widespread. Given the growing interdependence of nations in an increasingly globalized world, ultimate success at eliminating tuberculosis will require nations to look beyond their borders and attend to global disparities in the burden of this disease.

We are indebted to Barry Brause, Barry Hartman, Michael Oppenheim, and Kent Sepkowitz for sharing their experience and expertise in tuberculosis; and to Joseph Fins for our discussions on the ethical issues pertaining to tuberculosis screening, civil liberties, and public health.

\section{REFERENCES}

Additional references for this article are listed in Supplementary Appendix 3 (available with the full text of the article at http://www.nejm.org).

1. Gushulak BD, MacPherson DW. Population mobility and infectious diseases: the diminishing impact of classical infectious diseases and new approaches for the 21st century. Clin Infect Dis 2000;31:776-80. 2. Talbot EA, Moore M, McCray E, Binkin NJ. Tuberculosis among foreignborn persons in the United States, 1993-1998. JAMA 2000;284:2894-900 3. Tuberculosis cases and case rates per 100,000 population by origin: United States, 1991-2001. Atlanta: Centers for Disease Control and Prevention, 2002. (Accessed November 8, 2002, at http://www.cdc.gov/ nchstp/tb/surv/surv2001/pdf/Tabpost4.pdf.)

4. 2000 Decennial census. Washington, D.C.: Census Bureau, 2002.

(Accessed November 8, 2002, at http://www.census.gov/population/ www/socdemo/foreign.html.)

5. Geng E, Kreiswirth B, Driver C, et al. Changes in the transmission of tuberculosis in New York City from 1990 to 1999. N Engl J Med 2002; 346:1453-8

6. Targeted tuberculin testing and treatment of latent tuberculosis infection. MMWR Morb Mortal Wkly Rep 2000;49(RR-6):1-51.

7. Geiter L, ed. Ending neglect: the elimination of tuberculosis in the United States. Washington, D.C.: National Academy Press, 2000.

8. Coker R, van Weezenbeek KL. Mandatory screening and treatment of immigrants for latent tuberculosis in the USA: just restraint? Lancet Infect Dis 2001;1:270-6

9. Espinal MA, Laszlo A, Simonsen L, et al. Global trends in resistance to antituberculosis drugs. N Engl J Med 2001;344:1294-303.

10. EuroTB. Surveillance of drug resistance in Europe. European Commission, 2002. (Accessed November 8, 2002, at http://www.eurotb.org/.) 11. Weis SE, Moonan PK, Pogoda JM, et al. Tuberculosis in the foreignborn population of Tarrant County, Texas, by immigration status. Am J Respir Crit Care Med 2001;164:953-7.
12. Gold MR, Siegel JE, Russell LB, Weinstein MC, eds. Cost-effectiveness in health and medicine. New York: Oxford University Press, 1996. 13. Comstock GW, Baum C, Snider DE Jr. Isoniazid prophylaxis among Alaskan Eskimos: a final report of the Bethel isoniazid studies. Am Rev Respir Dis 1979;119:827-30.

14. Fairshter RD, Randazzo GP, Garlin J, Wilson AF. Failure of isoniazid prophylaxis after exposure to isoniazid-resistant tuberculosis. Am Rev Respir Dis 1975;112:37-42.

15. Immigration and Naturalization Act, $\$ 212,8$ U.S.C. 1182. Washington, D.C.: Immigration and Naturalization Service, 2002. (Accessed November 8, 2002, at http://www.ins.usdoj.gov/graphics/lawsregs/INA.htm.)

16. Drug topics red book: pharmacy's fundamental reference. Montvale, N.J.: Medical Economics, 2000.

17. National physician fee schedule payment amount file. Baltimore: Centers for Medicare \& Medicaid Services, 2000. (Accessed November 8, 2002, at http://cms.hhs.gov/physicians/pfs/default.asp.)

18. Medicare payment systems: clinical lab diagnostic fee schedule. Baltimore: Centers for Medicare \& Medicaid Services, 2002. (Accessed November 8,2002 , at http://cms.hhs.gov/paymentsystems/default.asp.)

19. Journey to work and place of work. Washington, D.C.: Census Bureau, 2002. (Accessed November 8, 2002, at: http://www.census.gov/ population/www/socdemo/journey.html.)

20. Passenger fares summary. Washington, D.C.: American Public Transportation Association, 2002. (Accessed November 8, 2002, at: http:// www.apta.com/stats/fares/fares.htm.)

21. Motor gasoline retail prices. Washington, D.C.: Department of Energy, 2002. (Accessed November 8, 2002, at http://www.eia.doe.gov/mer/ txt/mer9-4.)

22. Motor vehicle mileage, fuel consumption, and fuel rates. Washington, D.C.: Department of Energy, 2002. (Accessed November 8, 2002, at http://www.eia.doe.gov/emeu/mer/txt/merl-10.)

23. Healthcare Cost and Utilization Project, 1997. Rockville, Md.: Agency for Healthcare Research and Quality, 2002. (Accessed November 8, 2002, at http://www.ahrq.gov/data/hcup/hcupnet.htm.)

24. Medicare provider and analysis review (MEDPAR) of short-stay hospitals. Baltimore: Centers for Medicare \& Medicaid Services, 2002. (Accessed November 8, 2002, at http://cms.hhs.gov/statistics/medpar/ default.asp.)

25. Brown RE, Miller B, Taylor WR, et al. Health-care expenditures for tuberculosis in the United States. Arch Intern Med 1995;155:1595-600. 26. National employment and wage data from the Occupational Employment Statistics survey by occupation, 2000. Washington, D.C.: Bureau of Labor Statistics, Department of Labor, 2002. (Accessed November 8, 2002, at http://www.bls.gov/news.release/ocwage.t01.htm.)

27. Schwartzman K, Menzies D. Tuberculosis screening of immigrants to low-prevalence countries: a cost-effectiveness analysis. Am J Respir Crit Care Med 2000;161:780-9.

28. Diagnostic standards and classification of tuberculosis in adults and children. Am J Respir Crit Care Med 2000;161:1376-95.

29. Efficacy of various durations of isoniazid preventive therapy for tuber culosis: five years of follow-up in the IUAT trial. Bull World Health Organ 1982;60:555-64.

30. Gordin F, Chaisson RE, Matts JP, et al. Rifampin and pyrazinamide vs isoniazid for prevention of tuberculosis in HIV-infected persons: an international randomized trial. JAMA 2000;283:1445-50

31. A double-blind placebo-controlled clinical trial of three antituberculosis chemoprophylaxis regimens in patients with silicosis in Hong Kong. Am Rev Respir Dis 1992;145:36-41.

32. Geiter LJ. Results of a randomized, controlled trial to assess the toxicity and patient adherence with two short course regimens for the preven tion of tuberculosis, a two-month regimen of rifampin and pyrazinamide or a four-month regimen of rifampin only, in comparison with a control regimen of six-months-isoniazid. (Ph.D. [Epi] thesis. Baltimore: School of Hygiene and Public Health, Johns Hopkins University, 1997:180.)

33. King MD, Abdulrahman S, Oladele A, Tapia JR, Stringer E, Blumberg HM. A randomized trial of 2 months of rifampin plus pyrazinamide versus 6 months of isoniazid for the treatment of latent tuberculosis infection in HIV negative patients. In: Abstracts of the Infectious Diseases Society of America 39th Annual Meeting, San Francisco, October 25-28, 2001:1146. abstract. 34. Cook PP, McNeill EL, Allen M. Comparison of a two month regimen of pyrazinamide and rifampin with a six month regimen of isoniazid for treatment of patients with latent tuberculosis infection. In: Abstracts of the Infectious Diseases Society of America 39th Annual Meeting, San Francisco, October 25-28, 2001:1147. abstract.

35. Jasmer RM, Saukkonen JJ, Blumberg HM, et al. Short-course rifampin and pyrazinamide compared with isoniazid for latent tuberculosis infection: a multicenter clinical trial. Ann Intern Med 2002;137:640-7. 
36. Nolan CM, Goldberg SV, Buskin SE. Hepatotoxicity associated with isoniazid preventive therapy: a 7-year survey from a public health tuberculosis clinic. JAMA 1999;281:1014-8.

37. Kochanek KD, Smith BL, Anderson RN. Deaths: preliminary data for 1999. National vital statistics reports. Vol. 49. No. 3. Hyattsville, Md.: National Center for Health Statistics, 2001. (DHHS publication no. (PHS) 2001-1120 PRS 01-0358.)

38. Countries \& regions. Washington, D.C.: World Bank Group, 2001. (Accessed November 8, 2002, at http://www.worldbank.org/html/ extdr/regions.htm.)

39. Dye C, Scheele S, Dolin P, Pathania V, Raviglione MC. Global burden of tuberculosis: estimated incidence, prevalence, and mortality by country: WHO Global Surveillance and Monitoring Project. JAMA 1999;282:677-86.

40. Statistics. Washington, D.C.: Immigration and Naturalization Service, 2002. (Accessed November 8, 2002, at http://www.ins.gov/graphics/ aboutins/statistics/.)

41. Zuber PL, McKenna MT, Binkin NJ, Onorato IM, Castro KG. Longterm risk of tuberculosis among foreign-born persons in the United States. JAMA 1997;278:304-7.

42. Tuberculosis cases in foreign-born persons by number of years in the United States: states, 2000. Atlanta: Centers for Disease Control and Prevention, 2002. (Accessed November 8, 2002, at http://www.cdc.gov/ nchstp/tb/surv/surv 2000/pdfs/t20.pdf.)

43. Multiple cause-of-death public-use file for 1997 data. Hyattsville, Md. National Center for Health Statistics, 1997 (software).

44. National Tuberculosis Surveillance System. Atlanta: Centers for Disease Control and Prevention, 1996-2000 (data base).

45. Feeny DH, Furlong W, Boyle M, Torrance GW. Multiattribute health states classification systems: Health Utilities Index. Pharmacoeconomics 1995; 7:490-502.

46. A controlled clinical comparison of 6 and 8 months of antituberculosis chemotherapy in the treatment of patients with silicotuberculosis in Hong Kong. Am Rev Respir Dis 1991;143:262-7.
47. Moore M, Onorato IM, McCray E, Castro KG. Trends in drug-resistant tuberculosis in the United States, 1993-1996. JAMA 1997;278:833-7. [Erratum, JAMA 1998;279:656.]

48. Update: fatal and severe liver injuries associated with rifampin and pyrazinamide for latent tuberculosis infection, and revisions in American Thoracic Society/CDC recommendations - United States, 2001. MMWR Morb Mortal Wkly Rep 2001;50:733-5.

49. Bass JB Jr, Farer LS, Hopewell PC, et al. Treatment of tuberculosis and tuberculosis infection in adults and children. Am J Respir Crit Care Med 1994;149:1359-74.

50. Lollock L. The foreign-born population in the United States, March 2000. Current population reports. No. P20-534. Washington, D.C.: Census Bureau, 2001.

51. Consumer price indexes. Washington, D.C.: Bureau of Labor Statistics, Department of Labor, 2002. (Accessed November 8, 2002, at http:// www.bls.gov/cpi.)

52. Chaisson RE, Armstrong J, Stafford J, Golub J, Bur S. Safety and tolerability of intermittent rifampin/pyrazinamide for the treatment of tuberculosis infection in prisoners. JAMA 2002;288:165-6.

53. McGlynn KA, Lustbader ED, Sharrar RG, Murphy EC, London WT. Isoniazid prophylaxis in hepatitis B carriers. Am Rev Respir Dis 1986;134 666-8.

54. Sadaphal P, Astemborski J, Graham NM, et al. Isoniazid preventive therapy, hepatitis $\mathrm{C}$ virus infection, and hepatotoxicity among injection drug users infected with Mycobacterium tuberculosis. Clin Infect Dis 2001;33:1687-91.

55. Granich RM, Moore M, Binkin NJ, Mcray E. Drug-resistant tuberculosis in foreign-born persons from Mexico, the Philippines, and Vietnam — United States, 1993-1997. Int J Tuberc Lung Dis 2001;5:53-8.

Copyright (C) 2002 Massachusetts Medical Society.

\section{JOURNAL INDEX}

The index to volume 346 of the Journal can be ordered in a printed and bound format or can be downloaded from http://www.nejm.org. To order a bound copy, please call 1-800-217-7874 from the United States and Canada (call 651-582-3800 from other countries, or e-mail info@reprintservices.com). The cost is $\$ 17.50$. 